\title{
Importance of Social Workers in Multidisciplinary Frontline Environment During Pandemics
}

\author{
Dunya Ahmed \\ Dept. of Social Science \\ University of Bahrain \& International Institute of Inspiration Economy \\ E-mail: dr.dunya@ hotmail.com
}

Received: October 1, 2020 Accepted: October 26, 2020 Published: December 5, 2020

doi:10.5296/iss.v9i1.18035 URL: https://doi.org/10.5296/iss.v9i1.18035

\begin{abstract}
This pandemic was exaptational for lots of professions; however, the focus was mainly on medical staff front-liners. In this paper, we explore the different role of the social workers in alleviating the human-factor of the COVID-19 patients and their families

The methodology of this study considers the multidisciplinary approaches that could enhance the social workers' role; since COVID-19 pandemic was not only a medical issue, but also a social issue. The study recommends a national governing body is set and to enforce standard practices as per the guidance of the social workers. The implication of the study shows the need for social workers in the new normal and the type of training and competency needed. A framework is proposed to prepare social workers pre-, during- and after-pandemics.
\end{abstract}

Keywords: COVID-19 Pandemic, Social work, Multidisciplinary, New-normal, Frontline worker 


\section{MIN Macrothink}

\section{Introduction}

When people talk about front line worker, they think immediately about healthcare staff, with less attention given to other disciplines such as social workers, police, psychologist, etc. A study by Berg-Weger and Morley (2020) showed that social workers work was the most important professional to alleviate the challenges with most vulnerable during COVID-19.

Social workers are found today in a variety of organisations such as healthcare services, nursing homes, residential communities, and social service agencies. Their presence is so essential, and it is part of the health and safety of these groups during the crisis. Thus, they face challenges, such as the need to develop new ways to keep communication with families in time of lockdown and developing new activities that keep social distancing. They also played lots of other roles inside hospitals with children, young asylum seekers and others (Malcolm \& Margaret, 2020).

As a profession, social workers are exposed to all type of risks. In addition, they noted able to serve in the way they should with having all these numbers. However, in lots of situations, the service of the social workers was not given priorities, especially in less developed countries, where in the long run may cause more complications.

The literature still has a gap in addressing the role of the social workers to be part of a multidisciplinary framework that would address all the types of pandemic challenges in its spillovers. Also, there is no clear framework that addresses social workers for a similar future crisis that affect life and livelihood.

Working in partnership has many advantages for both people and the professionals involved as this allows the service user and their beneficiaries to be dealt with by different professionals with different skills. This helps the professionals as they are able to work in multi-professional teams and to work in multi-agencies. The multidisciplinary work brings together all of these.

In complex situations, social workers often have to deal with different agencies and professionals who would look at the beneficiary needs as a whole with all the influences surrounding them such as their hospitals, schools, etc. Hence, the social worker, in particular, can be an effective co-ordinator in different organisational mission teams to help the beneficiaries and link all the services together.

Although advances have been made in providing care and wellness in lots of countries around the world, there are often problems related to social services not being tailored to the needs and abilities of individuals. By considering that COVID-19 pandemic was not only a medical issue, as it was a more social issue, were in lots of countries violence, divorce, suicide, and other social problems increased, as a result of focusing on the pandemic from health perspective mainly (Buheji \& Ahmed, 2020b). 


\section{MlMacrothink}

\section{Literature Review}

\subsection{Social Workers and Multidisciplinary Work}

Multidisciplinary working refers to team working (networking), which will allow different professional groups to work together towards specific goals. For example, a study concerning the roles of social workers in these teams identified that professionals can exchange their objectives (Biggs, 1997).

In this way, the role of social work will extend to undertaking care management even, possibly, at the expense of reducing social workers' current role as professional advocates. In doing this, however, they would face other challenges, such as defining the boundaries between specialist and generic approaches within care management, and between care management and social work (Cambridge, 1999).

One could the role of a social worker in a multidisciplinary team in simple terms is to deal with issues related to social care. However, this is a vague explanation and does not address the complex role of a social worker. It is worth noting that it is a common misconception to state simply that social workers are there to assist the weakest members of society (Brayne \& Martin, 2001).

There are differences between health and social care; however, advocacy is one of the most important roles that social workers have (Middleton, 1995). Social workers deal with a range of issues, such as advocacy, make service users' viewpoints heard, assess needs, offer services, and to monitor the process of providing social care in general in order to render a service that is quite rigid in its structure but accessible.

Generally, social workers and other professionals, depending on their workload, may find themselves working on a number of cases simultaneously.

Figure 1 gives an example of integration and relation between the dimension between the type of clients (beneficiaries) served by the social worker, and the dimension of social services setting (social service users) for social workers. As shown in Figure 1 the social workers have a huge scope which can be multiplied if we consider their different roles in the different beneficiaries and service users organisations. This figure also shows the clear and cross-cutting role of the social workers, with illustration for an example of patients being the clients in different settings. This species should be experienced now during the COVID-19 pandemic (Thompson, 2002; Buheji \& Buheji, 2020).

Social workers often have the role in a multi-professional activity of being concerned with managing boundaries between agencies, disciplines and professions and have the role of communicating with families of the beneficiaries (clients), the service agencies (sittings) and the professionals of others disciplines. Their capacity to create harmony and cross the boundaries of the different professions ensure an affective outcome which is highly needed during the new normal and the challenges. 


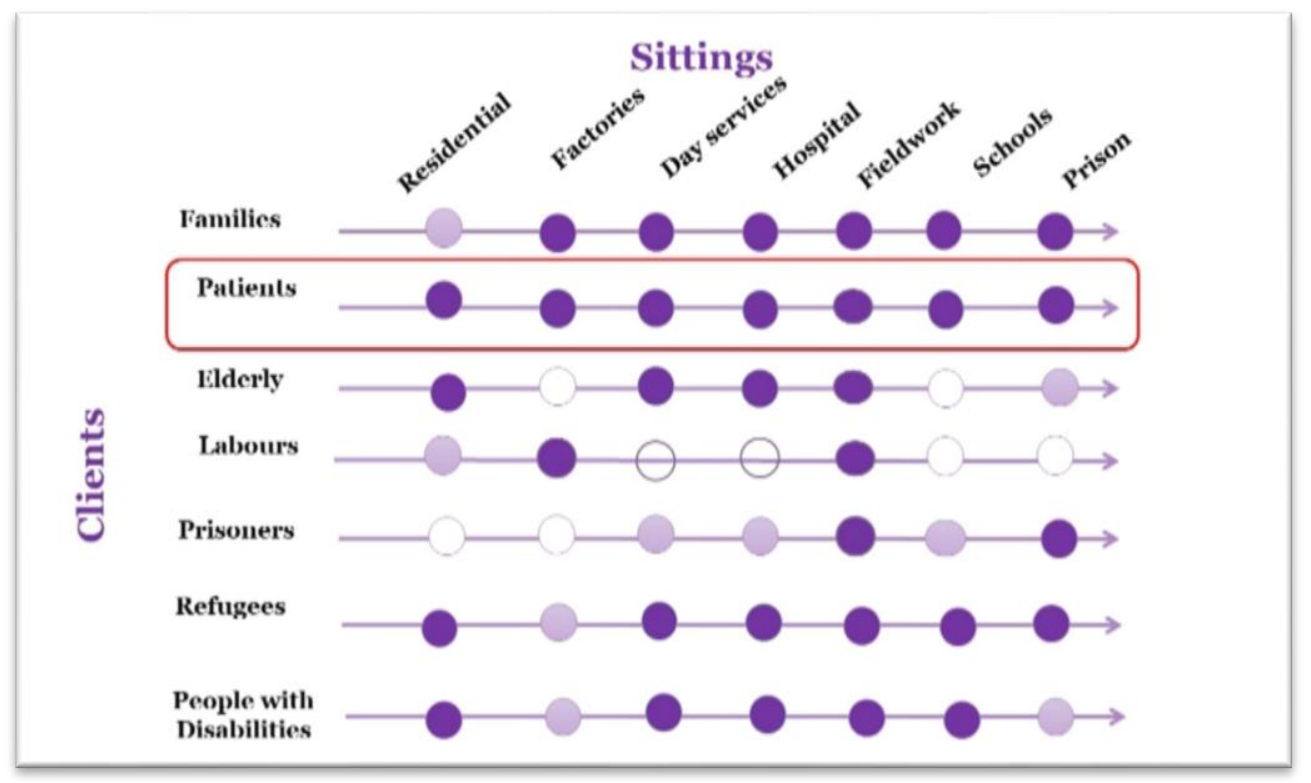

Figure 1. Examples of social workers clients and sitting

\subsection{Relationships between Social Workers and Other Professionals}

Providing the required care may need a number of professionals working together around the individual case. The role of the social worker within such teams is of vital importance. His/her role is to work in partnership with other professionals such as psychologists, psychiatrists, physiotherapists, nurses, day centre managers, etc. and hence s/he needs to understand the role of each team member so that consultation and communication channels can be established quickly should an urgent crisis arise.

It could be difficult, however, for social workers to fulfil their roles when they are working in a multidisciplinary team, as duties and roles constantly change. The contribution and duties of the social worker cover a large scope of activities (Payne, 2002). The traditional role of social workers has almost been superseded by the care manager role (O'Hara \& Sperlinger, 1997). For instance, the changes being implemented could be confusing as the role of social workers is thinly stretched to cover areas like budgeting and care services purchasing. It could also be a source of frustration as social workers' roles in multi-professional activities are shifted to be concerned more with management and co-ordination between agencies, disciplines and professions for the benefits of the service users agencies (sittings) and with obtaining resources from the government and communities. In addition, the process of building co-operation may not be easy because social workers and professionals will need to be aware of ways of dealing with clients.

The confidence factor plays important role in the social workers service delivery. Some families may not trust the social worker or even the professionals and they may prefer to look for the services by themselves and to deal with each professional separately. In such cases, the process of building co-operation will be degraded. Moreover, professionals should have equal power within a multidisciplinary team so that the roles of each are well defined with no 
overlapping tasks. There should also be a multilateral way of sharing experience so that professionals can learn from each other. Moreover, clients and carers should have power and join forces to fulfil the way clients want to live. For the professionals, multidisciplinary work may require more of their time, but the experience will be equally rewarding as it involves interaction with other professionals and sharing of knowledge.

Social workers use assessment skills, interview techniques, and counselling to define the needs of both the clients and service users. Informal knowledge is utilised by the social workers to exploit the resources available while managing to meet clients' needs. The target is to optimise the know-how to make the best use of the resources available. Therefore, the social worker is required to establish and extend efforts towards a good collaboration with other service providers. This requires that each social worker have the competency of good teamwork (Ahmed, 2002). This would guarantee the flow and exchange of knowledge and experience between the social workers and other professionals.

\subsection{Relationships between Social Workers and Clients}

Social workers have particular roles according to the type of setting and client requirements. These roles might include, for example, advocacy, by using the power of the organisation which social workers may need in some situations. In other cases, the social worker would have to play the role of counselling, to inform and guide clients. While in many other situations, the social worker would utilise casework as part of their service.

It is very important social workers should not forget to work on-group work in which they can let a group of people work together because they may have the same feelings and share the same problems. Additionally, social workers may help the groups by using networks, which means to help them be in touch with the community and exchange information and experiences. However, the social workers would need help in managing changes in attitudes. In other situations, these workers need to deal with the legislation to ensure the stability of the services provided (Middleton, 1995).

Social workers can see the client from different perspectives according to the situation and the setting. For example, while medical staff will look from a medical viewpoint, the agency will look from the perspective of how they can provide for them a particular element of care or service. The social worker has to look at the case as a whole from different aspects to show the family the services available, and to consider the links between the family, agencies and professionals in multidisciplinary work, which make them look at things from human factor rather than normal procedure.

Social care and social work often adopt the role in the multi-professional activity of being concerned with managing boundaries between agencies, disciplines and professions for the benefits of clients, gaining resources from the state and communities for clients. The other professions focus on their client, while social workers get support from the family, the community and other agencies. Limits are one aspect of the identity of a profession, agency or discipline, and being aware of boundaries alerts other agencies, professional concerns and disciplines. Boundaries tell us what the social rules are. In social work, going beyond 
boundaries makes social workers meet other colleagues (Payne, 2002).

\section{Methodology}

Based on the synthesis of the literature, the role of the social workers during the COVID-19 pandemic is explored, with more in-depth exploration is taken about enhancing role of social workers in multidisciplinary work during pandemics. The importance of specific human factor that addresses the uprising needs to social workers is proposed. The human factors extracted based on the incidents and the challenges reviewed in the various literature and publications. The review highlighted the social workers role and need in the new-normal, accordingly a framework is proposed.

\section{Social Workers in Time of COVID-19}

\subsection{Role of Social Workers in time of Crises}

Social work is a profession that was developed in the time of crises and focus mainly on venerable groups, as they are trained for such times. For example, using teleservices in communicating with clients and families during lockdowns, for example, tele-social workers in nursing homes reduce family anxiety, increase trust, and free up the nursing staff to provide resident care (Bern-Klug \& Beaulieu, 2020), and add the human factor to the service. By considering that human care from all prospective is essential for social development (Khairy, 2017).

During COVID-19 pandemic, the utilisation of the social workers varied in different countries. For example, a Jordanian study shows that the social workers could fulfil their roles effectively, which lead to a gap that was addressed by the volunteers from community (Al Gharaibeh, 2020).

\subsection{Pressures on Social Workers in Times of Crises}

In the current COVID-19 pandemic, most of the frontline professions were and are under pressure, which may be due to the lack of preparation and expectation. Social workers were not exceptional, while pressure was not only as a result of a load of work, as much as it was difficulties in providing services in the way they are used to and distance with their clients whine they in need for them mostly, or in other situation, they keep clients away from their families when they know that they need them most. A study by Bern-Klug and Beaulieu (2020), highlighted how the pandemic affected negatively on social workers psychosocially when they see frequent infected or pass away cases in nursing homes. However, they are trained to face such situation and emotional chaos so they can support others.

Other pressure faced by social workers that are highlighted in this study, is not giving social care and services priorities in lots of agencies, which not only affect the service as much as it pressurised in staff.

\subsection{Abilities of Social Workers in Facing Crises}

Absences of human-factor on most of the health services during the pandemic, with all communication via tele-services or faces behind masks and shields. Therefore, it is 
recommended that all health and social staff get special training regard the new way of communication in the new normal (Sagara et al., 2020). A more caring environment should be provided for them, whether through support for their family, special organisations, social workers, or other professionals. Social workers will have a large part to play in this initiative because advising and networking is one of the social workers' roles (Middleton, 1995). A study by Dauti et al. (2020), evaluated role pf social workers upon COVID-19, and recommended more role for social workers in policymaker decisions.

Social worker role was clearer with venerable groups such as elderly, people with disabilities and refugees or providing social services online (Dauti et al., 2020). Thus, their role with people infected by COVID-19 and their families was not really highlighted in lots of countries. In some countries few social workers used social media to continue their advocacy role in the time of COVID-19 toward venerable groups especially (Omorogiuwa, 2020; Amadasun, 2020; International Federation of Social Workers [IFSW], 2020).

\section{Social Workers in the New-Normal}

\subsection{What Social Workers Need?}

It is recognised that a competent and a confident workforce is an essential component of modern social services and yet, unlike health care professionals and teachers who have their respective national governing bodies to set and enforce standards of practice, social workers and other social care staff do not yet have comparable bodies, even though they often have access to people's confidential and intimate lives. Therefore, it is recommended to have a state policy that supports social workers role (Naylor et al., 2020).

Social workers' thus have an ethical obligation to bring in structured changes that break down barriers and challenge oppressive structures and practices (Stainton, 2002). However, the government gives more priority to funding health care services than social care services. As well as the inequality in funding between agencies, there is also inequality in power distribution between professionals (Clarke, 1996). The environment during a pandemic should also be considered for different professions (Sagara et al., 2020; Do Geimer-Flanders, 2009).

\subsection{Training for Social Workers}

Today, most of the social care staff, who provide the bulk of day-to-day care, have no recognised qualifications or training. This may directly contribute to the public perception that social services fail to support. To ensure that effective and high-quality services are maintained, well-trained and qualified staff are needed to carry out the tasks of social care. Equally important is co-ordination between staff from different care services such as health, day and residential care, etc. so that the well-being of clients efficiently improved (Williams, 1995), which will affect positively in their social quality of life (Haddou \& Lakmeche, 2020).

Clear planning, defining goals and holistic assessment will do good practice for social work (Thompson, 2002). Although advances have been made in providing care, there are often problems related to services not being tailored to the needs and abilities of individuals. As in 
other professions, it is important that professionally qualified social workers base their practice on the best evidence of what works for clients and are responsive to new ideas from research. Their early education and training will play a significant part in encouraging a flexible, intelligent approach to practice in later years and assist social workers in taking personal responsibility for their continuing professional education and development.

Education and training play important role in providing and improving social service awareness for all (Ahmed \& Albuarki, 2017). The study by Buheji and Buheji (2020) emphasized the requirements for employees in the new normal, by preparing individuals to be ready in time of pandemics, and introduced a toolkit to help employees to be more resilient in such times. Such approaches should be used for training social workers for time of pandemics.

\subsection{Social Workers Competency in the New Normal}

The social worker needs to have good interpersonal and communication skills, and the ability to organise and co-ordinate effectively. In personal terms, they must be anti-oppressive and must be able to plan care solutions holistically and creatively, as well as to be adept at problem-solving. They need to possess a clear perspective of the systems within which they work, be able to take preventative measures, have a sound knowledge base and be practising negotiators.

Amongst their many challenging duties, the social workers could carry-out assessments (including risk assessments). They also can do the exercise of crisis-intervention. Thus, the social worker can help in encouraging empowerment, organising and maintaining specific packages of care, or report-writing, networking, multi-tasking, balancing-conflicts perspectives and needs, nurturing specific situations, giving supporting care, and mentoring. They must provide encouragement, build relationships, and be able to supervise or line-manage others.

As counsellors, the social worker, in any situation, could certainly be called upon to manage aggression and high-risk scenarios, and may even be part of abuse investigations. They could also be involved in liaison and team building activities where they have a facilitating function. Finally, they must have a firm grasp of the knowledge base that underpins their work; this includes legislation, financial systems and funding, use of I.T., social work values, and risk and strategic planning. For instance, a social worker needs to have interpersonal and communication skills in order to build quickly and effectively trustworthy relationships with client and other professional colleagues (Middleton, 1995). Also, the social worker has the role of offering advocacy of rights and care service entitlement that is available to care users.

In addition to the above roles and skills, a social worker will build up career experience in other roles such as training skills, supporting functions (carers, parents, administration, clients, professionals, staff etc.), ethical work (equity and future change), sociological/ social policy perspectives, preventative work, policies and legislation, and co-ordination.

Consequently, Middleton (1995) and Thompson (2002) suggest that social workers should establish and follow some practical guidelines. The first stage should be to start assessing and 
gathering information about the situation so as to establish the seriousness of the problem and to address the needs of the people concerned, the risk factors involved, the strength and availability of resources for the individual, families or groups. In short, they need to understand the situation and the possible plan of action. In that this stage, there should be executed by taking into account all the factors surrounding the client as this would contribute to building up confidence and establish a trustworthy relationship. Equally important is establishing a good working relationship based on mutual trust with other professionals involved with the same case, so as to facilitate an exchange of views and ideas, together with effective collaboration to find the best solution. The nature of a social worker's job dictates that they co-operate with other professionals such as psychiatrists and psychologists to diagnose and prescribe effective care solutions for their service users. Marchant and Page (1992) carried out a study on relationships between professionals, showing that professionals sometimes find it difficult to establish a good working relationship with their clients. It is here where a social worker's help can be invaluable in performing the role of a mediator, building communication channels between professionals, clients, and their families. The last stage, but not the least, is ending and evaluating the case so that one can look back and see what can be learnt from the experience as this will serve as a future reference for similar cases (Thompson, 2002).

It is worthwhile mentioning that the process of social worker services should be carried out iteratively and with sufficient flexibility so that any mistake at any stage can be corrected without delay. Moreover, all the stages should be undertaken in a partnership that is based on openness and trust, with an opportunity for empowerment, sharing the responsibility for the outcomes, and avoiding dependency (Thompson, 2002).

The role of every member of the team should be known to the social worker as s/he would be the one who should deal with each member and liaise with them at certain levels. Other team members may include professional psychologists, psychiatrists, etc, down to people who have limited contact with the service user. These need to be referred to for whatever reason. So, taking all these duties and responsibilities into account, the role of a social worker in providing necessary care. Hence, to help the social workers' cause, there is an urgent need for more public education and changes in attitudes. Also, the status of social workers in society should be valued more and encouragement should be directed to people that carry out the duty of caring for the vulnerable and weak in society; such professionals should be financially rewarded for their efforts.

\section{Proposed Framework}

Based on the literature review, including the latest body of knowledge published on COVID-19 pandemic, there is a clear need for re-organising the present system to ensure in includes promoting social care services. The presence of a new framework should support more client (beneficiaries) independence and improve equity in the services life and livelihood provided.

To ensure that the social care workforce is fit to deliver modern, high-quality services through improvements in training arrangements, all staff need to play their part in moving 
social workers away from the public perception of an association with dependence to the promotion of independence. This will achieve the provision of safer services for children and a modern "enabling" service for adults. In this, the social worker must have support by; Defining clearly their roles and the way they carry out their employment duties; Setting up individual objectives that match service objectives; Having adequate supervision and management structures; Improving their education and training to meet the requirements of new policies.

Social workers play a fundamental role in generally dealing with issues related to social care. Their role primarily is to make care services accessible to service users. In addition, the social worker's role covers issues like advocacy and monitoring, and checking is undertaken to ensure that adequate social and health care is provided. Hence, social workers need to have different skills such as counselling, interview techniques, and being able to deal effectively with both service users and other professionals, such as psychologists, psychiatrists, nurses, etc.).

Naylor et al. (2020), suggested strategy to mitigate the pandemic effect, by training health workers from the community to engage them in early assessments and interventions for less severe cases, so social workers deal with complex ones. In addition to the need for selective training for social workers.

Cree (2009) argues that because of the implemented changes, social workers could see their role in the future evolving into that of advisors and facilitators, and further, to become budget holders when they are assigned to manage, assess and arrange packages of care for service users. It could also mean that the employer they work for may no longer be solely in a social work setting or in a social services department as it could be in GP surgeries, schools and hospitals, or they may become care providers in the voluntary or the private sector. Through this period of change in the nature of social work, it is normal that social workers may feel that they are under pressure from others as they face these mutations. Therefore, there may be the danger that social workers may find themselves pushed, either willingly or unwillingly, into working outside the scope of their confidence, skills and ability.

Tele was used by social workers as a support tool (Bryant et al., 2018; Pollack, 2008), thus study by Nisanci et al. (2020), emphasised how tele-social workers was increased and became crucial during the pandemic. Thus, it had lots of challenges as a result of being away from clients, with lots of missing in observation with absents of field visits and availability on the internet.

Figure 2 shows a simplified diagram of suggested skills process for social workers, to enable them to be ready in time of pandemic and for the new-normal. The framework below suggests the availability and readiness of the social workers in all the settings and for all the type of the clients (the beneficiaries) across the three main periods, i.e. pre-pandemic, during emergency disasters (or pandemic), after the pandemic (i.e. in the new normal). 


\section{MInstitute Macrothink}

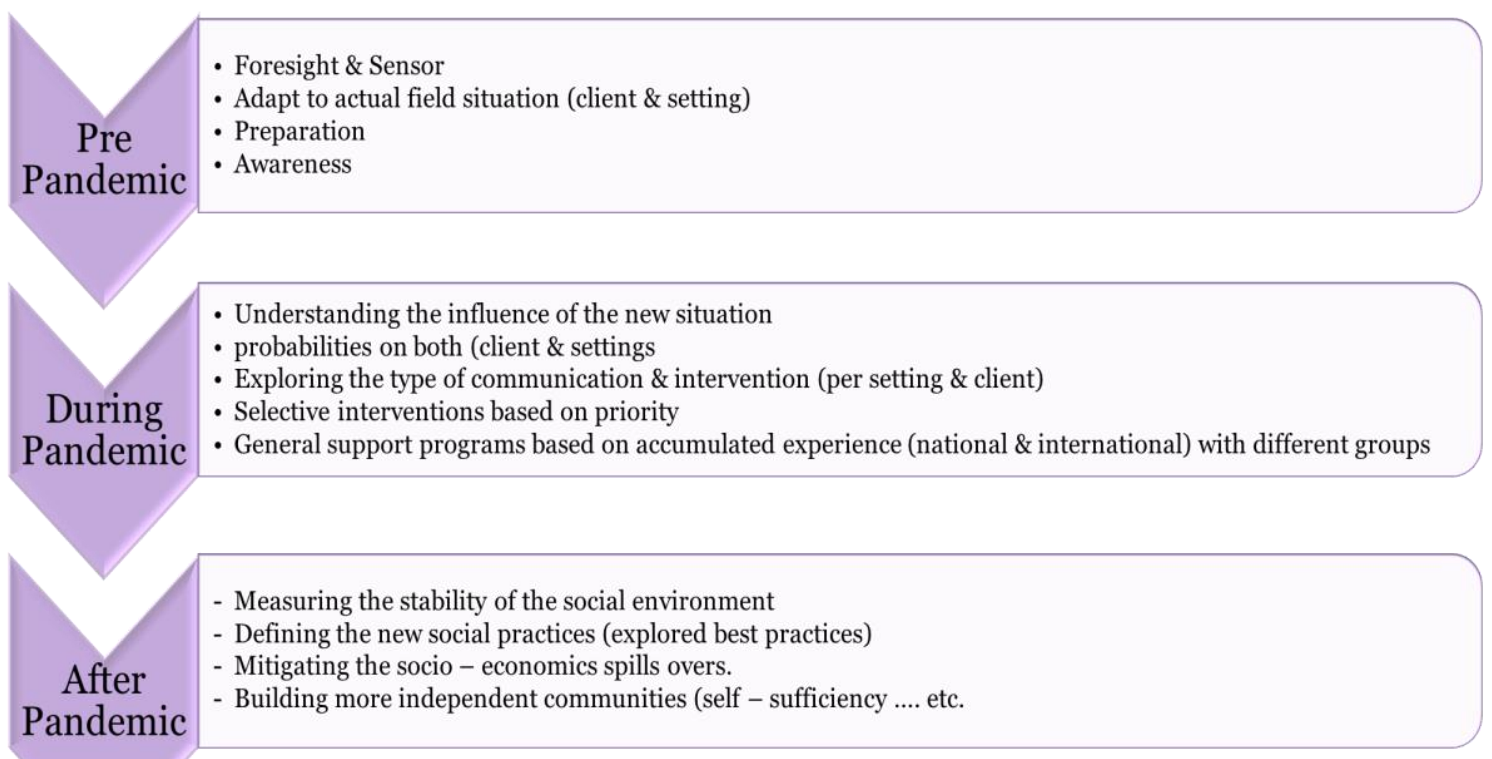

Figure 2. Social-works skills process

In conclusion, this pandemic may bring lots of opportunities in improving role and context of social work as a profession, and insight multidisciplinary (Buheji \& Ahmed, 2020a; Buheji, 2020).

\section{Conclusion}

This paper highlighted the importance of social workers role in the time of the pandemic, and showed the essence of their role specifically in a multidisciplinary setting. The social worker role with serval client groups and different settings could give them a wide range of duties and different possibilities that could add value to both the different professions or community services outcomes. Specifically, this work focused on the optimisation of the role of the social worker during global emergency situations as in the COVID-19 pandemic.

There is a need for more preparation to face future coming challenges, including potential pandemics, or natural disasters which needs different competencies and preparedness. Absence of actual field study was a limitation for of this study; therefore, it is highly recommended that further empirical research studies are done to analyse the impact of the presence or the absence of the social workers services during COVID-19. The other limitation of this paper, is that it did not focus on the challenges that face the social worker in a multidisciplinary environment such as the need for effective collaboration and conflicts management between the different professionals.

There are many opportunities that could be traced to how social workers could creatively solve problems related to socially related healthcare service during the pandemic. Such opportunities are also expected to carry a great impact on the current protocols of how services are delivered in all means of life, including the way governments prioritise its 
deployment of support services during national emergencies.

In general, any absence of the social workers' effective role could be clearly seen in any community. The un-utilisation of social services at the right time and place is certainly could an important cause for different direct and indirect negative effects and spillovers. This can be observed clearly with the increase of anxiety, or violence, as an example in many countries around the world during the pandemic. While more social problems may come up in later stages, that are not expected or well-studied.

\section{References}

Ahmed, D. (2002). The Role of Social Work in Multidisciplinary Working with People with Disability. University of Nottingham.

Ahmed, D., \& Albuarki, J. (2017). Review of the Challenges of Scientific Research in the Arab World and Its Influence on Inspiration Driven Economy. International Journal of Inspiration \& Resilience Economy, $\quad 1(1), \quad 28-34$. http://article.sapub.org/10.5923.j.ijire.20170101.04.html

Al Gharaibeh, F. (2020). The response of Jordanian society and social workers to the COVID-19 crisis. International Social Work, Article in press. https://doi.org/10.1177/0020872820944989

Amadasun, S. (2020). Social Work for Social Development in Africa. Ibadan: September Publishing House.

Berg-Weger, M., \& Morley, J. E. (2020). Loneliness and Social Isolation in Older Adults during the COVID-19 Pandemic: Implications for Gerontological Social Work. J Nutr Health Aging, 24, 456-458. https://doi.org/10.1007/s12603-020-1366-8

Bern-Klug, M., \& Beaulieu, E. (2020). COVID-19 Highlights the Need for Trained Social Workers in Nursing Homes. Journal of the American Medical Directors Association, 21(7), 970-972. https://doi.org/10.1016/j.jamda.2020.05.049

Biggs, S. (1997). Interprofessional Collaboration: Problems and Prospect. In J. Ovretveit, P. Mathias, \& T. Thompson (Eds.), Interprofessional Working for Health and Social Care. England, Macmillan. https://doi.org/10.1007/978-1-349-13873-9_10

Brayne, H., \& Martin, G. (2001). Law for Social Workers. U.K.: Blackstone Press Limited.

Bryant, L., Garnham, B., Tedmanson, D., \& Diamandi, S. (2018). Tele-Social Work and Mental Health in Rural and Remote Communities in Australia. International Social Work, 61(1), 143-55. https://doi.org/10.1177/0020872815606794

Buheji, M. (2020). Forward from "Editor in Chief": The New Normal -A New Era Full of Inspiration and Resilience after COVID-19. International Journal of Inspiration \& Resilience Economy 2020, 4(2).

Buheji, M., \& Ahmed, D. (2020a). Foresight of Coronavirus (COVID-19) Opportunities for a Better World. American Journal of Economics, 10(2), 97-108. 
https://doi.org/10.5923/j.economics.20201002.05

Buheji, M., \& Ahmed, D. (2020b). Planning for 'The New Normal' - Foresight and Management of the Possibilities of Socio-economic. Spillovers due to COVID-19 Pandemic. Business Management and Strategy, 11(1), 160-179. https://doi.org/10.5296/bms.v11i1.17044

Buheji, M., \& Buheji, A. (2020). Planning Competency in the New Normal- Employability Competency in Post-COVID-19 Pandemic. International Journal of Human Resource Studies, 10(2). https://doi.org/10.5296/ijhrs.v10i2.17085

Cambridge, P. (1999). Building Care Management Competence in Services for People with Learning Disabilities. British Journal of Social Work, 29, 393-415. https://doi.org/10.1093/oxfordjournals.bjsw.a011464

Clarke, J. (1996). After Social Work? In N. Parton (Ed.), Social theory, social change and social work. London, Routledge.

Cree, V. (2009). The changing nature of social work. In R. Adam, L. Dominelli, \& M. Payne (Eds.), Social Work: Themes, Issues and Critical Debates (3rd ed.). UK, Red Globe Press.

Dauti, M., Dhëmbo, E., Bejko, E., \& Allmuça, M. (2020). Rethinking the transformative role of the social work profession in Albania: Some lessons learned from the response to COVID19. International Social Work, 63(5), 640-645. https://doi.org/10.1177/0020872820940356

Do Geimer-Flanders, J. (2009). Creating a healing environment: rationale and research overview. Cleve. Clin. J. Med. 76 (April (2)), S67. https://doi.org/10.3949/ccjm.76.s2.13

Haddou, M., \& Lakmeche, M. (2020). Positive Psychology and Quality of Life. International Journal of Youth Economy, 4(2), 69-80.

International Federation of Social Workers (IFSW). (2020). Statement on IFSW and Covid19. Retrieved from https://www.ifsw.org/statement-on-ifsw-and-covid-19/

Khairy, H. (2017). Exploring the Implementation of Government Work Program towards Bahrain Economic Vision 2030 with Respect to Strategic and Project Management (A Retrospective Study for the Period 2011-2014). International Journal of Inspiration \& Resilience Economy, 1(1), 14-27.

Malcolm, G., \& Margaret, H. (2020). Social Work in the Time of the COVID-19 Pandemic: All in This Together? Br J Soc Work, 50(3), 637-641. https://doi.org/10.1093/bjsw/bcaa036

Marchant, R., \& Page, M. (1992). Child Protection Work with Children with Multiple Disabilities. London, National Society for the Prevention of Cruelty to Children.

Middleton, L. (1995). Making a Difference: Social Work with Disabled Children. U.K.: Venture Press.

Naylor, M., Hirschman, K., \& McCauley, K. (2020). Meeting the Transitional Care Needs of Older Adults with COVID-19. Journal of Aging \& Social Policy, 32(4-5), 387-395. https://doi.org/10.1080/08959420.2020.1773189 


\section{Macrothink}

Issues in Social Science

ISSN 2329-521X 2021, Vol. 9, No. 1

Nisanci, A., Kahraman, R., Alcelik, Y., \& Kiris, U. (2020). Working with refugees during COVID-19: Social worker voices from Turkey. International Social Work, 63(5), 685-690. https://doi.org/10.1177/0020872820940032

O'Hara and Sperlinger. (1997). Adults with Learning Disability: A practical approach for health professionals. England: Johan \& Sons.

Omorogiuwa, T. (2020). COVID-19 and older adults in Africa: Social workers' utilization of mass media in enforcing policy change. International Social Work, 63(5), 646-650. https://doi.org/10.1177/0020872820941748

Pollack, D. (2008). Social Work Comes to the Small Screen Legal Challenges of Tele-Social Work. International Social Work, 51(6), 841-6. https://doi.org/10.1177/0020872808095256

Sagara, R., Chawlab, N., \& Senc, M. (2020). Preserving the "human touch" in times of COVID-19. Asian Journal of Psychiatry, 54. https://doi.org/10.1016/j.ajp.2020.102224

Stainton, T. (2002). Learning Disability. In R. Adam, L. Dominelli, \& M. Payne (Eds.), Critical Practice in Social Work. UK, Palgrave.

Thompson, N. (2002). Social Work With Adults. In R. Adam, L. Dominelli, \& M. Payne (Eds.), Social Work: Themes, Issues and Critical Debates (2nd ed). UK, Palgrave.

Williams, C. (1995). Invisible victims: Crime and abuse against people with learning disability. London, Jessica Kingsley.

\section{Copyright Disclaimer}

Copyright for this article is retained by the author(s), with first publication rights granted to the journal.

This is an open-access article distributed under the terms and conditions of the Creative Commons Attribution license (http://creativecommons.org/licenses/by/3.0/). 